Research Article

\title{
Distribution and Risk Factors of Water-Related Accidents for General Aviation Aircraft
}

\author{
Ruiliang Yang $\mathbb{D}$, LibinYang $\mathbb{D}$, Lina Zhao $\mathbb{D}$, and Donghan Geng $\mathbb{D}$ \\ Key Laboratory of Modern Electromechanical Equipment Technology, Tiangong University, Tianjin 300387, China \\ Correspondence should be addressed to Donghan Geng; fisherw@163.com
}

Received 9 June 2020; Revised 20 January 2021; Accepted 2 February 2021; Published 10 February 2021

Academic Editor: Jiaqiang E

Copyright ( 2021 Ruiliang Yang et al. This is an open access article distributed under the Creative Commons Attribution License, which permits unrestricted use, distribution, and reproduction in any medium, provided the original work is properly cited.

\begin{abstract}
In the past two decades, dozens to more than a hundred people have died each year in water-related accidents, most of which general aviation has accounted for. To identify the distribution and risk factors of fatal water-related accidents for general aviation aircraft, a total of 594 water-related accidents according to 14 CFR Part 91 from 2009 to 2019 were chosen from the National Transportation Safety Board's online database. A two-step approach, consisting of a univariable logistic regression and a multivariable logistic regression, was performed to estimate the effects of 28 parameters. Results show that aircraft with a rated power of more than 100 horsepower (odds ratio $>5$ ), instrument conditions (odds ratio $=25.585$ ), flying night operations (odds ratio $=3.717$ ), and cruise phase (odds ratio $=11.699$ ) possessed an elevated risk for a fatal outcome. This research is the first to identify the distribution and risk factors of fatal water-related accidents under 14 CFR Part 91 . The necessity and importance of survival equipment for water-related accidents are also highlighted in this paper.
\end{abstract}

\section{Introduction}

An aircraft accident is defined by Title 49 Code of Federal Regulations Part 830 as "an occurrence associated with the operation of an aircraft which takes place between the time any person boards the aircraft with the intention of flight and all such persons have disembarked, and in which any person suffers death or serious injury, or in which the aircraft receives substantial damage." According to the wellestablished human factors analysis and classification system, the cause of aircraft accident can often be attributed to organizational influences, unsafe supervision, preconditions for unsafe acts, and unsafe acts [1].

Water-related accidents are aircraft accidents that involve an emergency landing on water, in which planned water-related accidents are called ditching accidents [2]. Dozens to more than a hundred people have died in waterrelated accidents every year in the past two decades. Figure 1 shows the fatalities and involved occupants in water-related accidents from 1999 to 2019. Each year, fatalities due to water-related accidents ranged from 30 to 195 with the number of involved occupants in these accidents ranging from 101 to 506. Although the overall trends of fatalities and involved occupants have downward in the past two decades (see Figure 1), water-related accidents still deserve special attention because they are particular, i.e., occupants in water-related accidents require additional survival equipment to help them survive. It is estimated that approximately $70 \%$ of the fatalities in water-related accidents were attributed to drowning [3]; therefore, aircraft should be equipped with survival equipment to save more lives during overwater operations.

General aviation (GA) implies all flights except those of scheduled airlines and uniformed armed flights [4]. In recent years, the fatal accident rate of GA operations under 14 CFR Part 91 fell below 1 fatal event per 100,000 hours [5]. Fatal injury is defined by 49 CFR 830.2 as "any injury which results in death within 30 days of the accident." Impact is often the main cause of traffic deaths [6,7], Similarly, the most important cause of death in aircraft accidents is also impact, followed by fire and drowning [8]. The death in waterrelated accidents can also be attributed to these three categories, but the possibility of drowning increased significantly. The literature on GA safety has focused on the causes and 


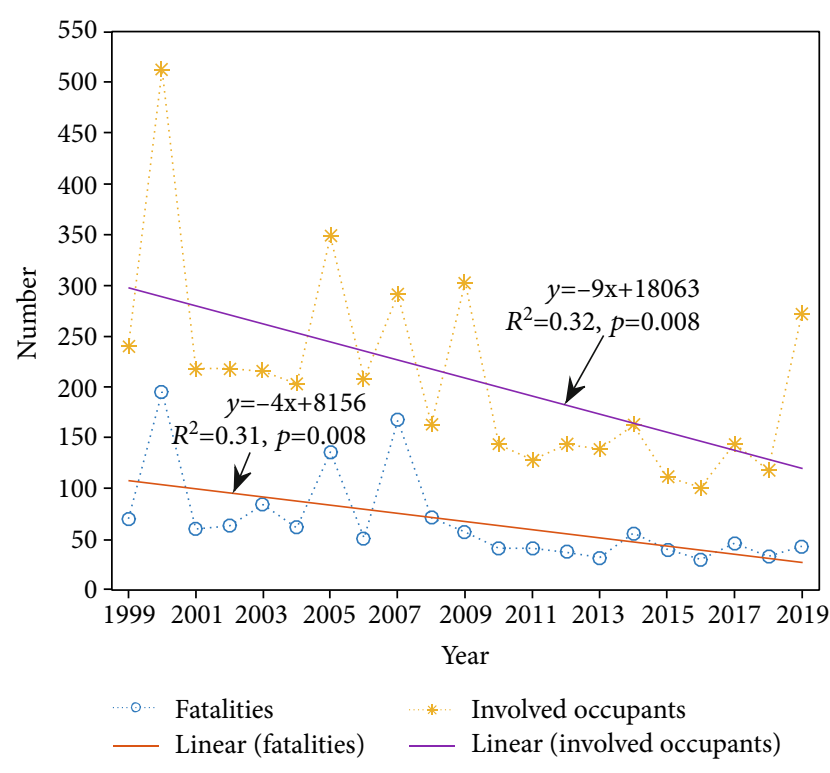

Figure 1: Fatalities and involved occupants in water-related accidents from 1999 to 2019 . The equations in the figure are linear regression equations, $r^{2}$ is the coefficient of determination, and $p$ is the significant value. Data source: https://www.ntsb.gov/_layouts/ ntsb.aviation/index.aspx.

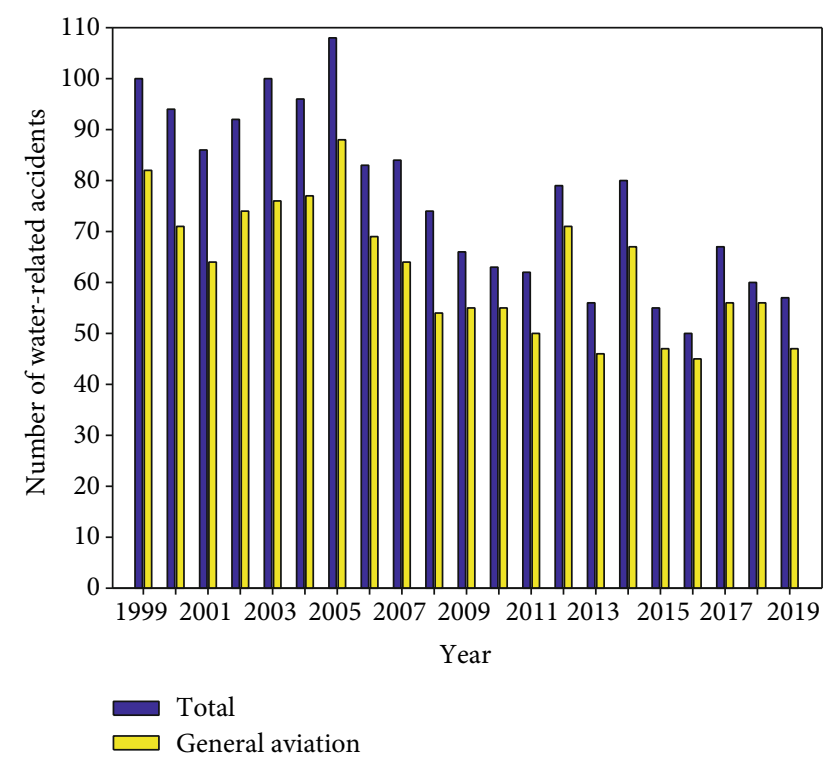

FIGURE 2: The number of water-related accidents from 1999 to 2019. Data source: https://www.ntsb.gov/_layouts/ntsb.aviation/index.aspx.

trends of GA [9] and human error [10] and models [1]. GA accounted for the overwhelming majority of civil aviation accidents and fatalities in the United States. Similarly, most of the water-related accidents from 1999 to 2019 occurred in GA (see Figure 2). The ratio of GA water-related accidents to total water-related accidents ranges from $75.7 \%$ to $86.2 \%$. However, no literature researching GA water-related accidents has been published.

R.G.W. Cherry \& Associates Limited also [11] presented a review of accident data and existing research applicable to aircraft water-related accidents from 1967 to 2009. But their research only includes water-related accidents involving western-built airplanes certified for 20 or more passengers under CAR 523/FAR 23/CS-23, only some of which were general aviation aircraft. The report discussed 81 waterrelated accidents occurring in 43 years, of which only 31 accidents had official accident reports. The US Federal Regulations 49 CFR 830 specifies which aircraft accident occurrences must be reported to the National Transportation Safety Board (NTSB), which means that only 31 accidents from 1967 to 2009 in the report are considered formal aircraft accidents. In reality, the number of water-related accidents ranged from 49 to 107 every year from 1999 to 2018 (see Figure 2), which is more than the total number of formal accidents reported by R.G.W. Cherry \& Associates Limited [11]. Furthermore, the report did not consider the distribution and risk factors of water-related accidents. Therefore, the objective of the present study is to show the distribution of water-related accidents of GA operating under 14 CFR Part 91 and to identify the risk factors that lead to the fatal crashes for the period spanning 2009-2019.

\section{Methods}

All accident reports under 14 CFR Part 91 were downloaded from the NTSB online database (https://www.ntsb.gov/_ layouts/ntsb.aviation/index.aspx). Water-related accidents under 14 CFR Part 91 were chosen by carefully reading these reports. Because there were many missing items in the reports from 1999 to 2008, this study analyzes only the reports from 2009 to 2019.

All statistical analyses were performed using SPSS (v22) software. Logistic regression was used to identify the risk factors for fatal accidents. To solve the problem of missing data for several parameters, a two-step approach that consisted of a univariable logistic regression and a multivariable logistic regression [12] was performed. A univariable logistic regression was used to choose the significant parameters, and a multivariable logistic regression was used to statistically adjust the estimated effects of each significant parameter.

\section{Results}

3.1. Water-Related Accident and Injury Distributions. There were 594 water-related accidents, of which 220 were fatal accidents and 374 were nonfatal accidents in GA operating under 14 CFR Part 91 from 2009 to 2019. Of the 594 waterrelated accidents, 580 accidents occurred in the United States. In addition, 8, 3, 1, 1, and 1 accidents occurred in Bahamas, Kiribati, Gulf of Mexico, and Atlantic Ocean, respectively. The number of annual water-related accidents ranged from 45 to 71 (see Figure 3), and the number of involved occupants ranged from 87 to 125 (see Figure 4). There were 12 to 25 fatal accidents each year that resulted in 22 to 47 fatalities. Annual nonfatal accidents are significantly higher than fatal accidents, and the annual fatalities accounted for approximately $40 \%$ of the involved occupants. 


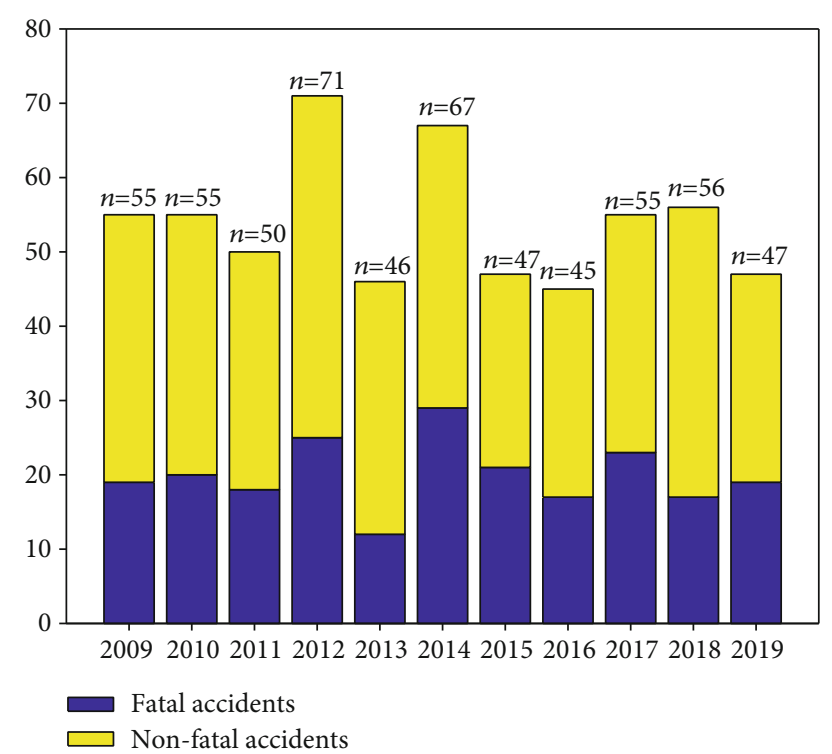

FIGURE 3: Water-related accident distribution in GA operating under 14 CFR Part 91 in 2009-2019. $n$ denotes the number of total accidents.

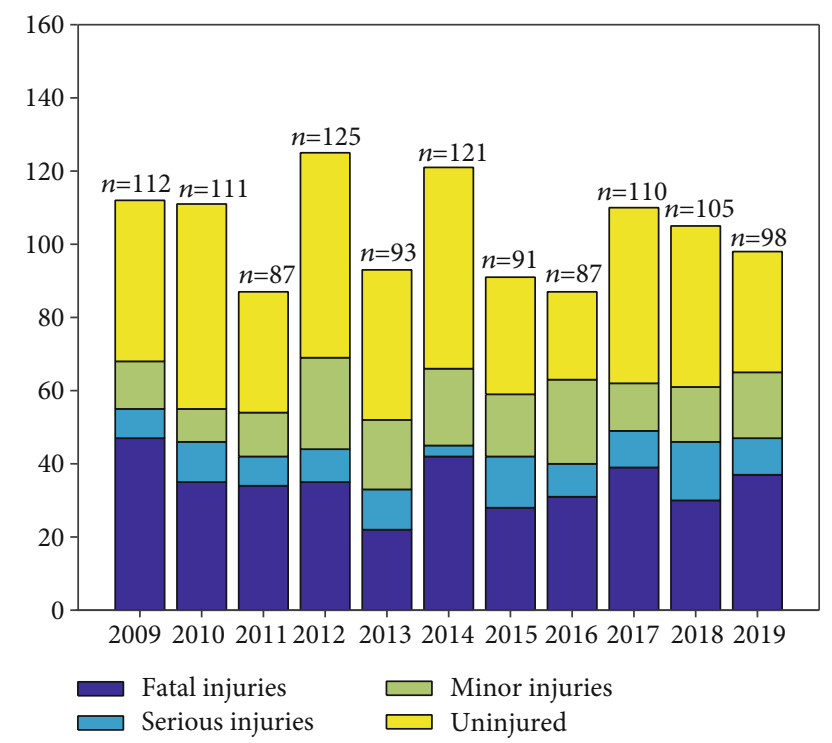

Figure 4: Injury distribution of water-related accidents in GA operating under 14 CFR Part 91. $n$ denotes the number of total injuries for each year.

3.2. Ditching Location of Water-Related Accidents. Accident reports were used to identify ditching locations. If an aviation accident report did not mention the ditching location, the latitude and longitude were used to determine the ditching location through Google Maps. Figure 5 shows the ditching locations of water-related accidents in GA operating under 14 CFR Part 91. There were 8 types of ditching locations: lake/lagoon, gulf/bay/estuary, ocean/sea, river/creek, marsh/swamp, pond/pool/reservoir, canal/water lane/ditch/channel, and choppy water/standing water. The four most common ditching locations were lake/lagoon (189/594),

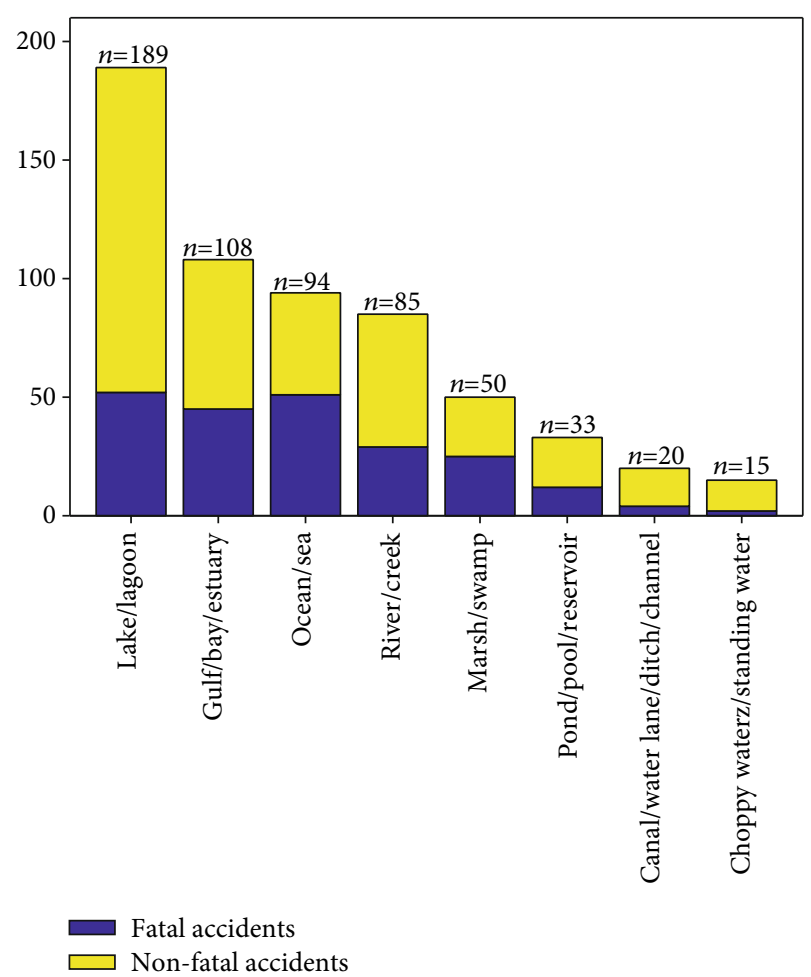

FIGURE 5: Ditching locations of water-related accidents in GA operating under 14 CFR Part 91. $n$ denotes the number of waterrelated accidents in each type of ditching location.

gulf/bay/estuary (108/594), ocean/sea (94/594), river/creek (85/594), and marsh/swamp (50/594). Other smaller locations such as ponds acted as the ditching locations for 68 airplanes. When ditching occurred in the ocean or sea, the number of nonfatal accidents was lower than that of fatal accidents (43 nonfatal accidents versus 51 fatal accidents). When ditching in a marsh or swamp, the number of nonfatal accidents was equivalent to that of fatal accidents. In all the other cases, the number of nonfatal accidents was less than that of fatal accidents.

3.3. Risk Factors for Fatal Flights. There were 28 parameters used as risk factors for a fatal flight. These parameters were classified into four issues: pilot issue, aircraft issue, weather issue, and flight issue. Pilot issue included eight parameters: pilot certificate, occupational pilot, pilot age, pilot sex, second pilot present, pilot total flight time, pilot flight time of make/model, and instructor rating. Aircraft issue included eleven parameters: airplane rating, certified max gross weight, rated power, number of engines, engine type, airworthiness certificate, time since last inspection, airframe total time, seats, aircraft category, and amateur built. Weather issue included six parameters: weather conditions, conditions at accident site, conditions of light, visibility, wind speed/gusts, and precipitation and obscuration. Flight issue included three parameters: broad phase of flight, distance from the nearest shore, and purpose of flight. Except for the distance from the nearest shore, which was determined by the latitude, longitude, and Google Maps, the other parameters were all obtained from the accident reports. 
TABle 1: Univariable logistic regression for a fatal flight.

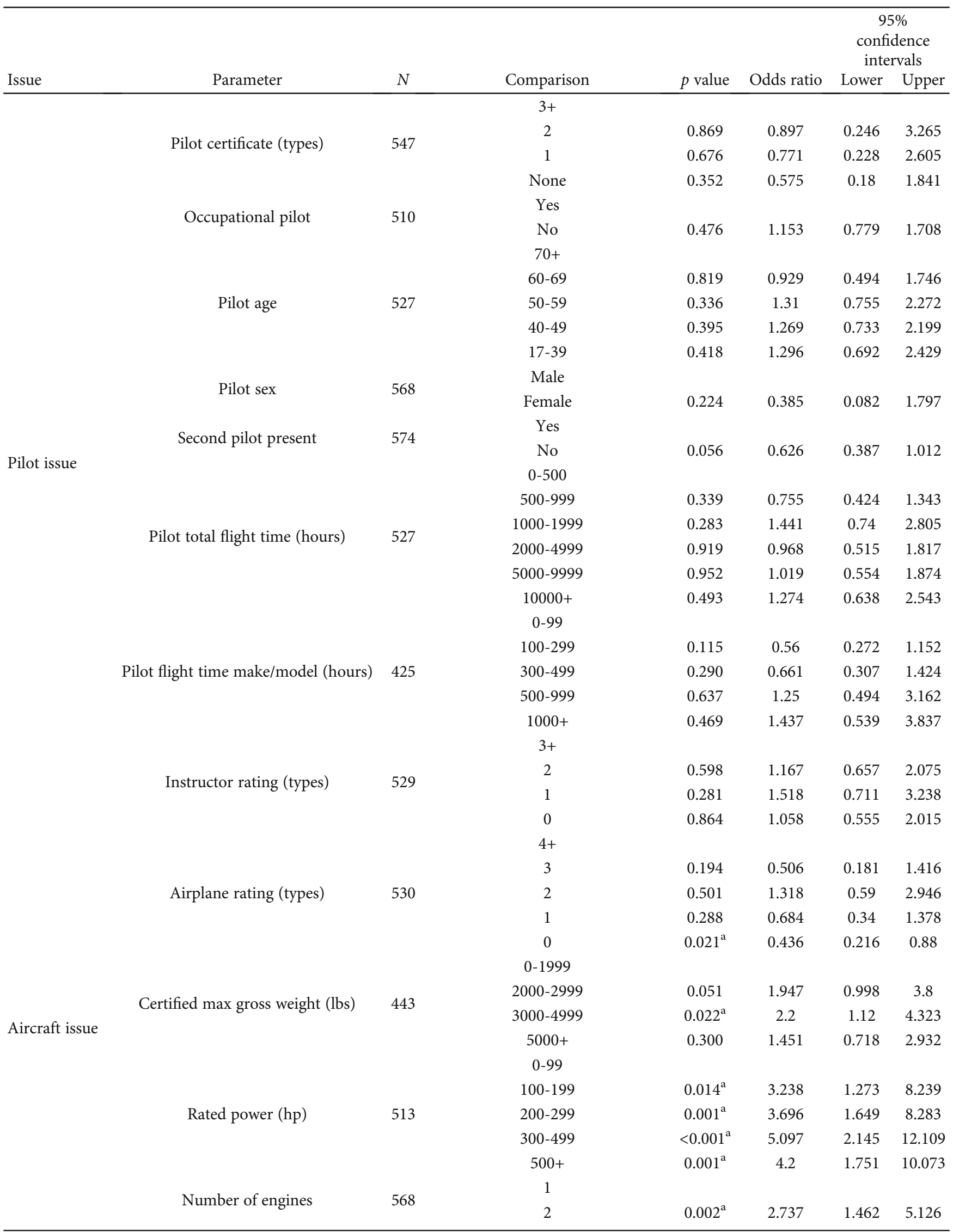


TABle 1: Continued.

\begin{tabular}{|c|c|c|c|c|c|c|c|}
\hline \multirow[b]{2}{*}{ Issue } & \multirow[b]{2}{*}{ Parameter } & \multirow[b]{2}{*}{$N$} & \multirow[b]{2}{*}{ Comparison } & \multirow[b]{2}{*}{$p$ value } & \multirow[b]{2}{*}{ Odds ratio } & \multicolumn{2}{|c|}{$\begin{array}{c}95 \% \\
\text { confidence } \\
\text { intervals }\end{array}$} \\
\hline & & & & & & Lower & Upper \\
\hline & Fnoine tyne & 582 & Turbo & & & & \\
\hline & Lingile type s s s & 302 & Reciprocating & $0.025^{\mathrm{a}}$ & 0.513 & 0.286 & 0.918 \\
\hline & & & Normal & & & & \\
\hline & Airworthiness certificate & 515 & Experimental & 0.842 & 0.934 & 0.476 & 1.833 \\
\hline & & & Other & 0.435 & 0.745 & 0.356 & 1.558 \\
\hline & & & $0-19$ & & & & \\
\hline & Time since lact incnection (hourc) & 175 & $20-49$ & 0.927 & 1.05 & 0.371 & 2.972 \\
\hline & 1 & 170 & $50-99$ & 0.782 & 1.167 & 0.392 & 3.471 \\
\hline & & & $100+$ & 0.277 & 0.544 & 0.182 & 1.629 \\
\hline & & & $0-499$ & & & & \\
\hline & A irframe total time (hours) & 444 & $500-999$ & 0.333 & 1.343 & 0.739 & 2.442 \\
\hline & 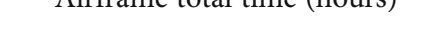 & 444 & $1000-4999$ & 0.403 & 0.745 & 0.373 & 1.486 \\
\hline & & & $5000+$ & 0.916 & 1.027 & 0.626 & 1.684 \\
\hline & & & 1 or 2 & & & & \\
\hline & Seats & 508 & 3 or 4 & 0.894 & 0.967 & 0.594 & 1.575 \\
\hline & & & $5+$ & 0.481 & 0.835 & 0.506 & 1.379 \\
\hline & Aircraft cateoory & 588 & Airplane & & & & \\
\hline & Hilcrall Calegory & 300 & Other & 0.902 & 0.968 & 0.574 & 1.631 \\
\hline & Amateur built & 591 & Yes & & & & \\
\hline & Aindeur vuit & 391 & No & 0.631 & 0.897 & 0.577 & 1.396 \\
\hline \multirow{16}{*}{ Weather issue } & & & VMC & & & & \\
\hline & Weatner condition & 580 & IMC & $<0.001^{\mathrm{a}}$ & 14.6 & 5.633 & 37.838 \\
\hline & Conditions at accident site & 584 & Visual conditions & & & & \\
\hline & Coniturionis at aceicient site & 304 & Instrument conditions & $<0.001^{\mathrm{a}}$ & 13.049 & 5 & 34.054 \\
\hline & Condition of light & 588 & Day & & & & \\
\hline & Conicitivit of 119it & 300 & Night/dark/dusk/dawn & $<0.001^{\mathrm{a}}$ & 3.783 & 2.231 & 6.414 \\
\hline & Vicihility & 573 & $0-9$ & & & & \\
\hline & Visidinty & $5 / 3$ & $10+$ & $<0.001^{\mathrm{a}}$ & 0.277 & 0.163 & 0.473 \\
\hline & & & Calm & & & & \\
\hline & Wind sneed/ousts (lnnots) & 580 & $2-4$ & 0.284 & 1.362 & 0.774 & 2.396 \\
\hline & vrima speed/gusts (Kinots) & 300 & $5-9$ & 0.872 & 0.958 & 0.566 & 1.62 \\
\hline & & & $10+$ & 0.129 & 0.724 & 0.476 & 1.099 \\
\hline & & & No precipitation; no obscuration; & & & & \\
\hline & Procinitation and shecurntion & 188 & Rain or snow or thunderstorm & 0.134 & 2.513 & 0.754 & 8.377 \\
\hline & Precipitation and ooscuration & 480 & Rain and fog & 0.331 & 0.5 & 0.124 & 2.022 \\
\hline & & & Fog & 0.816 & 1.2 & 0.257 & 5.593 \\
\hline \multirow{10}{*}{ Flight issue } & \multirow{6}{*}{ Broad phase of flight } & \multirow{6}{*}{468} & Takeoff & & & & \\
\hline & & & Maneuvering & 0.097 & 1.857 & 0.893 & 3.86 \\
\hline & & & Landing & 0.679 & 0.859 & 0.418 & 1.765 \\
\hline & & & Cruise & $<0.001^{\mathrm{a}}$ & 8.369 & 3.541 & 19.78 \\
\hline & & & Approach & 0.731 & 0.848 & 0.332 & 2.169 \\
\hline & & & Other & 0.928 & 1.04 & 0.439 & 2.465 \\
\hline & \multirow{4}{*}{ Distance (nautical miles) } & \multirow{4}{*}{588} & $0-0.9$ & & & & \\
\hline & & & $1-9.9$ & 0.100 & 2.921 & 0.813 & 10.49 \\
\hline & & & $10-49.9$ & 0.742 & 1.258 & 0.32 & 4.943 \\
\hline & & & $50+$ & 0.606 & 1.5 & 0.322 & 6.991 \\
\hline
\end{tabular}


TABLE 1: Continued.

\begin{tabular}{|c|c|c|c|c|c|c|c|}
\hline \multirow[b]{2}{*}{ Issue } & \multirow[b]{2}{*}{ Parameter } & \multirow[b]{2}{*}{$N$} & \multirow[b]{2}{*}{ Comparison } & \multirow[b]{2}{*}{$p$ value } & \multirow[b]{2}{*}{ Odds ratio } & \multicolumn{2}{|c|}{$\begin{array}{c}95 \% \\
\text { confidence } \\
\text { intervals }\end{array}$} \\
\hline & & & & & & Lower & Upper \\
\hline & & & Personal & & & & \\
\hline & Purpose of flight & 590 & Instructional & 0.102 & 0.667 & 0.41 & 1.084 \\
\hline & & & Other & 0.062 & 0.488 & 0.229 & 1.037 \\
\hline
\end{tabular}

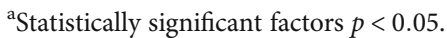

Of the 594 water-related accidents, only 84 accidents were complete with all 28 parameters of interest (listed in Table 1). Of the complete cases, there were 22 fatalities and 62 nonfatalities equating to a value of approximately 1 event per variable (22/28), far less than the recommended minimum value of 10 [13]. For this reason, a two-step approach was used to analyze the risk factors for fatal accidents. In the two-step approach, a fatal accident was chosen as the response variable, and each latent risk factor was chosen as the predictor variable.

Table 1 shows the results of the univariable logistic regression for evaluating the relationship between accidents and latent risk factors.

In the univariable logistic regression, all parameters regarding pilot issue were not associated with a diminished risk for a fatal accident. Similar to our findings, O'Hare et al. [14] showed that pilot characteristics were not the key determinants of an injury outcome. However, Bazargan et al. [15] showed that a fatal accident was more likely to be associated with male pilots, pilots that are 60 plus years old, and pilots with more experience. They suggested that female pilots made fewer fatal mistakes, and more experienced pilots were likely to pilot challenging flights. In fact, only 11 female pilots out of 594 pilots were involved in waterrelated accidents. The results of a statistical analysis show that no significant difference exists between male and female pilots, and because there were too few female pilot data, the gender comparison may be rendered meaningless [13]. Water-related accidents involve an emergency landing on water and are generally not related to the pilot's flight experience; thus, fewer years of pilot experience did not result in more fatal accidents.

Some parameters regarding aircraft issue such as airplane rating, certified max gross weight, rated power, number of engines, and engine type were identified as risk factors based on the univariable logistic regression. O'Hare et al. [14] and Boyd [12] also proved that twin-engine aircraft carried a higher risk of fatality due to different flight profiles. The parameters regarding weather issue such as weather conditions, conditions at accident site, conditions of light, and visibility were also identified as risk factors based on the univariable logistic regression. These findings partially coincide with Boyd [12], which showed that conditions at accident site and conditions of light both carried an excess risk for a fatal flight. The parameter, broad phase of flight, in the flight issue category was identified as a risk factor, and the difference between takeoff phase and cruise phase was statistically significant, but the difference between takeoff and other phases of flight was not statistically significant.

Therefore, some of the parameters regarding aircraft issue, weather issue, and flight issue do carry a higher risk for a fatal accident, whereas other parameters are associated with a lower risk. More specifically, 10 parameters have been identified as risk factors based on the univariable logistic regression: airplane rating, certified max gross weight, rated power, conditions at accident site, conditions of light, visibility, number of engines, engine type, weather conditions, and broad phase of flight.

Multiple-variable analysis using a frontward selection procedure was used to assess the risks for a fatal accident. At each step of the frontward selection procedure, the variable with the largest nonsignificant $p$ value was eliminated from the model. The final multiple-variable logistic regression model included four parameters: rated power, conditions at accident site, conditions of light, and broad phase of flight (see Table 2). There were 319 complete records available for multiple-variable logistic regression analysis (225 nonfatal and 94 and fatal accidents). The number of events per variable was therefore 23.5 (94/4), which far exceeds the necessary 10 number of events suggested by Peduzzi et al. [13].

Of the 28 parameters discussed in this paper, only four parameters (rated power, conditions at accident site, conditions of light, and broad phase of flight) were included in the final multivariable logistic regression, indicating that there was a significant association between the four risk factors and fatal accidents. The four parameters all contributed to a robust multivariable model (Chi - square $=95.924, p<$ 0.001 ) with a predictive value of $79.3 \%$. Whether from the univariable logistic regression or the multivariable logistic regression, aircraft with a rated power of more than 100 horsepower, operating under instrument conditions, flying night operations, and flying in cruise phase all showed an elevated risk for a fatal outcome. Furthermore, the odds ratio values also showed that the change direction of significant independent variables to the corresponding outcome variable is consistent when conducting univariable logistic regression and multivariable logistic regression.

Compared with an aircraft with less than 100 horsepower, an aircraft with larger horsepower was five times more likely to have a fatal water-related accident (odds ratio $>5$ ). The reason may be because aircraft with higher horsepower generally tend to fly longer distances over water, resulting in a higher risk for mortality. It can be seen from Figure 5 that 
TABLE 2: Multivariable logistic regression of risk factors for a fatal flight.

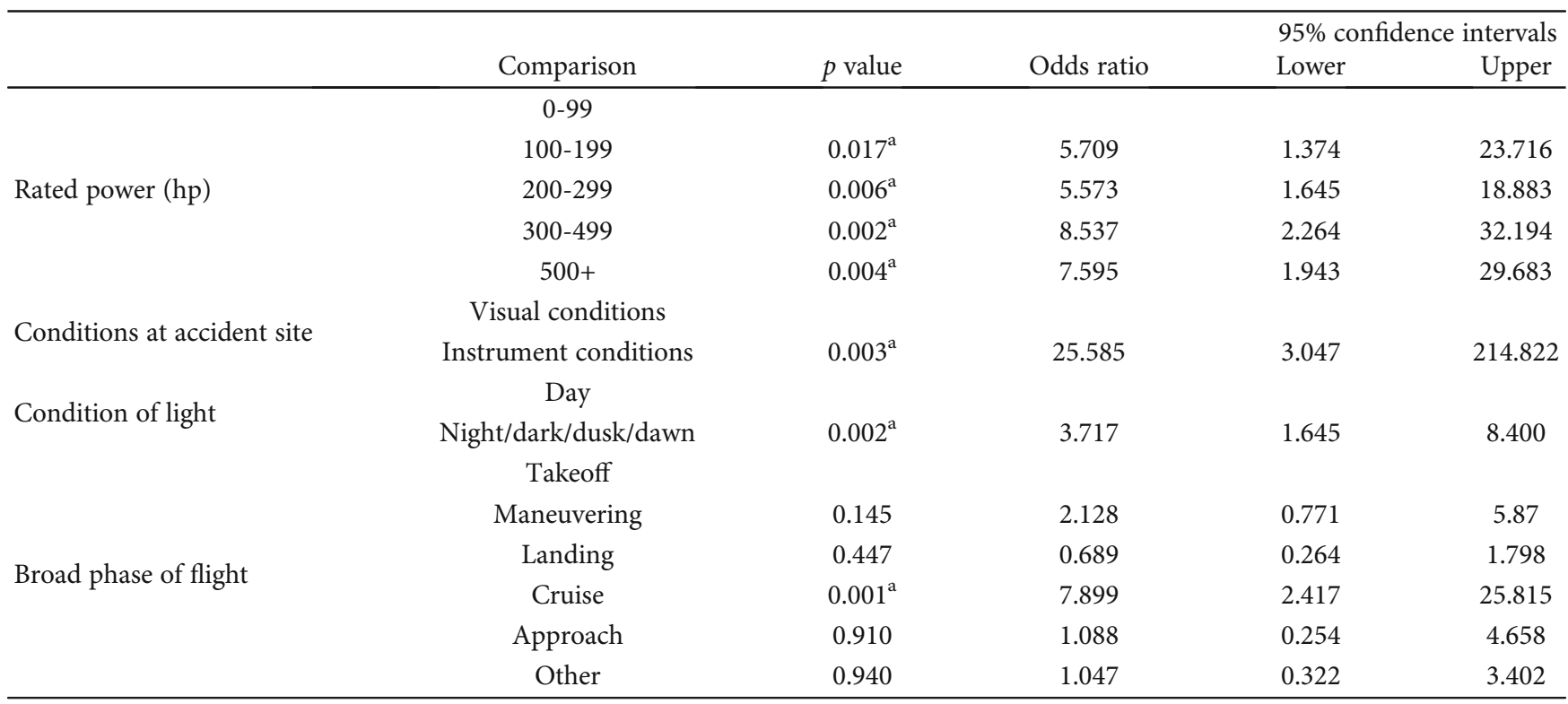

astatistically significant factors $p<0.05$.

the number of fatal accidents was greater than that of nonfatal accidents when ditching on the ocean or sea.

Operations under instrument conditions showed a greater risk of a fatal water-related accident than those under visual conditions (odds ratio $=25.585$ ), a conclusion of which is similar to that of Boyd [12]. Of the 319 complete records in the multiple-variable logistic regression model, 14 water-related accidents that occurred while operating under instrument conditions consisted of 13 fatal waterrelated accidents, whereas 305 water-related accidents that occurred while operating under visual conditions consisted of 81 fatal water-related accidents.

Night operations showed an excess risk for a fatal outcome (odds ratio $=3.717$ ). Of the 319 complete records, 280 water accidents that occurred during the day consisted of 69 fatal water-related accidents, whereas 39 water accidents that occurred during the night consisted of 25 fatal waterrelated accidents.

The difference between the takeoff phase and cruise phase was statistically significant. Compared to the takeoff phase, the cruise phase indicated an elevated risk for a fatal outcome (odds ratio $=11.699$ ). However, the difference in risk between the takeoff phase and other phases of flight was not statistically significant.

\section{Discussion}

To the author's knowledge, this is the first study to exclusively report the distribution and risk factors of waterrelated accidents in GA operating under 14 CFR part 91. A water-related accident is a unique accident that involves an emergency landing on water, in which specialized water emergency equipment may be used to save lives. According to 14 CFR 91.509, an aircraft should be equipped with a life preserver or an approved flotation device for each occupant of the aircraft when the flight is over water more than 50 nautical miles from the nearest shore. If the flight distance from the nearest shore is more than 100 nautical miles or the flight time is over 30 minutes, life preservers must be installed on the aircraft. As for other overwater operations under $14 \mathrm{CFR}$ part 91, survival equipment is not mandatory.

Of the 588 water-related accidents for which the distance from the nearest shore could be determined in this study, the distance was more than 50 nautical miles from the nearest shore for only 10 accidents. These accidents, which consisted of 6 fatal accidents and 4 nonfatal accidents, resulted in 10 fatalities with 21 involved occupants. Considering the 594 water-related accidents with 380 fatalities and 1140 involved occupants, it is unreasonable to have required only the aircraft in the 10 accidents to install survival equipment.

Because survival equipment was not required for the aircraft involved in most of the water-related accidents, many airlines and pilots often ignored the importance of having survival equipment on the aircraft. In the 594 water-related accident reports discussed in this paper, only 38 reports mentioned survival equipment, in which only 5 aircraft were installed with personal flotation devices and 23 aircraft installed with life preservers. In fact, survival equipment played a huge role in saving at least 24 lives, according to the NTSB online database. Thus, airlines and pilots should pay more attention to survival equipment. It is necessary to equip more planes, even those not intending to fly over water, with the appropriate survival equipment.

However, the aircraft in 7 water-related accidents was equipped with individual survival equipment, but the equipment was not in use at the time of the accidents. The main reason for this was because the passengers either did not know or were not familiar with how to use the survival equipment. Thus, more safety education regarding water-related accidents and survival equipment should be performed to pilots and passengers. 
TABLE 3: Comparison of life preservers and inflatable individual flotation devices.

\begin{tabular}{lcc}
\hline Feature & Life preserver & Inflatable individual flotation device \\
\hline Active TSO standard & TSO-C13g [18] & TSO-C72c [17] \\
Float chambers & One or two, often two & One \\
Minimum buoyancy & $16.3 \mathrm{~kg}$ & $6.4 \mathrm{~kg}$ \\
Reflective material & At least $25.8 \mathrm{~cm}^{2}$ of reflective material on each side & No required \\
Color & Approved international orange-yellow or similar high visibility color & No required \\
Survivor locator light & Yes & No required \\
Donning test & Yes & No required \\
Self-righting & Yes & No required \\
\hline
\end{tabular}

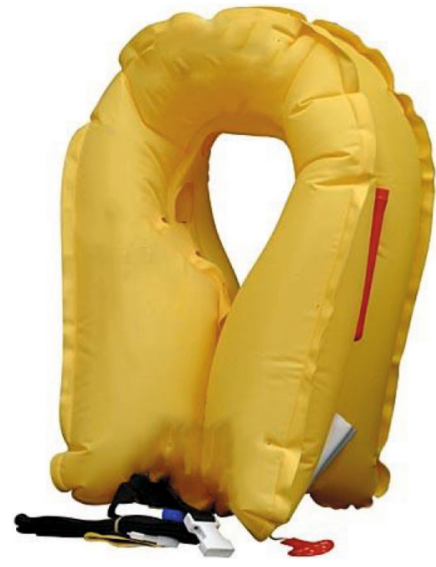

FIgURe 6: A typical life preserver.

Common individual survival equipment includes life preservers and inflatable individual flotation devices. A life preserver is a flotation device used by an aircraft occupant if the aircraft ditches on water and can sometimes be termed as "life jacket" or "life vest" in some aviation documents [16]. Individual survival equipment other than life preservers is defined as individual flotation devices, which should meet TSO-C72c [17]. There are two categories of individual flotation devices: noninflatable types and inflatable types. Noninflatable types typically include flotation seat cushions, headrests, armrests, and pillows, which serve other primary functions on a flight. Inflatable types can replace life preservers in some less demanding flights. Typical inflatable types have a similar form and function as life preservers but demonstrate a lower performance. Table 3 compares the different life preservers and inflatable individual flotation devices.

In general, life preservers typically have double float chambers and a survivor locator light (see Figure 6), which can meet more stringent performance requirements and be used in a flight with high safety requirements. Inflatable individual flotation devices have one float chamber with low performance (see Figure 7) and can only be used to replace life preservers in a flight with low safety requirements.

Aircraft with a rated power of more than 100 horsepower (odds ratio $>5$ ), operating under instrument conditions (odds ratio $=25.585$ ), and flying night operations (odds ratio $=3.717$ ) carried an elevated risk for a fatal outcome; therefore, aircraft flying under these conditions should be

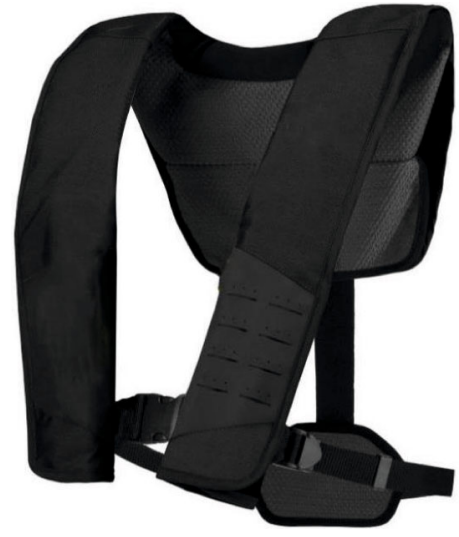

FIgURe 7: A typical inflatable individual flotation device.

equipped with survival equipment that meets high safety requirements such as life preservers to save more lives.

\section{Conclusions}

The distribution and risk factors of water-related accidents in general aviation aircraft were presented using a two-step approach. First, approximately $95.3 \%$ of the general aviation aircraft (566/594) involved in water-related accidents were not equipped with survival equipment, resulting in casualties. Therefore, aircraft operating under 14 CFR Part 91 should be equipped with survival equipment for each occupant of the aircraft to avoid the risk of injuries and death. Second, aircraft with a rated power of more than 100 horsepower (odds ratio $>5$ ), operating under instrument conditions (odds ratio $=25.585$ ), and flying night operations (odds ratio $=3.717$ ) carried an elevated risk for a fatal outcome; therefore, aircraft flying under these conditions should be equipped with survival equipment that meets high safety requirements such as life preservers to save more lives. Finally, because many airlines and pilots often ignore relevant knowledge about survival equipment, more safety education regarding water-related accidents and survival equipment should be conducted to airlines and pilots.

\section{Data Availability}

The datasets generated during and/or analyzed during the current study are available from the corresponding author on reasonable request. 


\section{Conflicts of Interest}

The authors declare that they have no conflicts of interest.

\section{Acknowledgments}

We would like to thank the National Natural Science Foundation of China (No. U1933111 and No. 51705361).

\section{References}

[1] M. C. G. S. P. Bandeira, A. R. Correia, and M. R. Martins, "General model analysis of aeronautical accidents involving human and organizational factors," Journal of Air Transport Management, vol. 69, pp. 137-146, 2018.

[2] NTSB (National Transportation Safety Board), Loss of thrust in both engines after encountering a flock of birds and subsequent ditching on the Hudson River US Airways Flight 1549 Airbus A320-214, N106US Weehawken, New Jersey, January 15, 2009, Report Number: NTSB/AAR-10/03, Washington, DC, 2010, May, 2010, https:/www.ntsb.gov/investigations/ AccidentReports/Reports/AAR1003.pdf.

[3] TSB (Transportation Safety Board), Loss of control and collision with water, Cochrane Air Service de Havilland DHC-2 Mk.1, Report Number: A12O0071, C-FGBF Lillabelle Lake, Ontario, 2012, https://tsb.gc.ca/eng/rapports-reports/ aviation/2012/a12o0071/a12o0071.pdf.

[4] M. Aguiar, A. Stolzer, and D. D. Boyd, "Rates and causes of accidents for general aviation aircraft operating in a mountainous and high elevation terrain environment," Accident Analysis and Prevention, vol. 107, pp. 195-201, 2017.

[5] D. D. Boyd, "General aviation accidents related to exceedance of airplane weight/center of gravity limits," Accident Analysis and Prevention, vol. 91, pp. 19-23, 2016.

[6] L. Hu, X. Hu, J. Wang, A. Kuang, W. Hao, and M. Lin, "Casualty risk of e-bike rider struck by passenger vehicle using China in-depth accident data," Traffic Injury Prevention, vol. 21, no. 4, pp. 283-287, 2020.

[7] L. Hu, X. Bao, M. Lin, C. Yu, and F. Wang, "Research on risky driving behavior evaluation model based on CIDAS real data," Proceedings of the Institution of Mechanical Engineers, Part D: Journal of Automobile Engineering, 2021.

[8] R. G. W. Cherry and A. Limited, Trends in Accidents and Fatalities in Large Transport Aircraft, Report Number: DOT/FAA/AR-10/16, Washington, DC, 2010, June 2010, https:// www.fire.tc.faa.gov/pdf/10-16.pdf.

[9] B. S. Shao, M. Guindani, and D. D. Boyd, "Causes of fatal accidents for instrument-certified and non-certified private pilots," Accident Analysis and Prevention, vol. 72, pp. 370375, 2014.

[10] K. Burns and C. Bonaceto, "An empirically benchmarked human reliability analysis of general aviation," Reliability Engineering \& System Safety, vol. 194, p. 106227, 2020.

[11] R. G. W. Cherry and A. Limited, Review and Assessment of Transport Category Airplane Ditching Standards and Requirements, Report Number: DOT/FAA/TC-14/8, Renton, WA, 2015, May 2015, https://www.fire.tc.faa.gov/pdf/tc-14-8.pdf.

[12] D. D. Boyd, "Causes and risk factors for fatal accidents in noncommercial twin engine piston general aviation aircraft," Accident Analysis and Prevention, vol. 77, pp. 113-119, 2015.

[13] P. Peduzzi, J. Concato, E. Kemper, T. R. Holford, and A. R. Feinstein, "A simulation study of the number of events per var- iable in logistic regression analysis," Journal of Clinical Epidemiology, vol. 49, no. 12, pp. 1373-1379, 1996.

[14] D. O'Hare, D. Chalmers, and P. Scuffham, "Case-control study of risk factors for fatal and non-fatal injury in crashes of rotary-wing aircraft," Journal of Safety Research, vol. 74, no. 10, 2003.

[15] M. Bazargan and V. S. Guzhva, "Impact of gender, age and experience of pilots on general aviation accidents," Accident Analysis and Prevention, vol. 43, no. 3, pp. 962-970, 2011.

[16] R. Yang, L. Wang, C. Zhou, S. Li, and D. Geng, "Life preservers: concepts, progress, and challenges," The International Journal of Aerospace Psychology, vol. 30, no. 3-4, pp. 77-88, 2020.

[17] TSO-C72c, "Individual floatation devices," Federal Aviation Administration, Washington, DC, 1990.

[18] TSO-C13g, "Life preservers," Federal Aviation Administration, DC, 2017. 